\title{
Functional Evaluation of Mid and Distal Penile Hypospadias Surgery with Special Reference to Uroflowmetry
}

\author{
Anand Pandey \\ Ajay N. Gangopadhyay \\ Vijayendra Kumar \\ Shiv P. Sharma \\ Dinesh K. Gupta \\ Saroj C. Gopal \\ Department of Pediatric Surgery, Institute of Medical Sciences, Banaras Hindu University, Varanasi, India
}

\section{Key Words}

Hypospadias • Uroflowmetry • Snodgrass urethroplasty • Mathieu urethroplasty

\begin{abstract}
Background: To assess two different operative techniques in hypospadias with special emphasis on urinary flow with the help of uroflowmetry. Material and Methods: In this prospective study, all patients underwent either Snodgrass or Mathieu urethroplasty. Preoperative uroflowmetry was done in every patient. Postoperative uroflowmetry was done 2 weeks after stitch removal only in those patients who were not having urethral fistula. Postoperative dilation was done only in those patients who had decreased urinary flow as compared to preoperative values. Results: Fifty patients were included in this 2-year study. Uroflowmetry was performed in 37 patients. Twenty-two patients underwent Snodgrass urethroplasty and the other 15 had Mathieu urethroplasty. Pre- and postoperative $\mathrm{Q}_{\max }$ values were $6.57 \pm$ 2.67 and $7.36 \pm 3.90 \mathrm{ml} / \mathrm{s}$, respectively. $Q_{\text {avg }}$ values were 4.16 \pm 1.87 and $4.52 \pm 2.50 \mathrm{ml} / \mathrm{s}$, respectively. Although statistically insignificant, the Snodgrass technique appeared to be relatively better than Mathieu's technique. Conclusion: Uroflowmetry can predict the need for dilation in hypospadias. The Snodgrass technique appears to be functionally better than Mathieu's technique. With avoidance of unnecessary trauma due to dilation, the cooperation of pediatric patients can be achieved.

Copyright $\odot 2011$ S. Karger AG, Basel
\end{abstract}

\section{KARGER}

Fax +41613061234

E-Mail karger@karger.ch

www.karger.com
(C) 2011 S. Karger AG, Basel

1015-9770/11/0054-0169\$26.00/0

Accessible online at:

www.karger.com/cur

\section{Introduction}

Hypospadias occurs following abnormal development of the penis [1]. More than 200 original techniques have been applied to correct hypospadias. Each of these techniques has some complications, the most common of which are fistula and meatal stenosis [2].

All the techniques emphasize the cosmetic outcome. In contrast to it, the documentation of the functional outcome has not been extensively elucidated. Uroflowmetry is one such measure. It is the measurement of the urinary flow with various parameters. Evaluation on the basis of uroflowmetry in toilet trained patients of hypospadias has been tried at a few centers with claims of satisfactory results [3]. This study attempts to assess two different techniques in mid and distal penile hypospadias with special emphasis on urinary flow with the help of uroflowmetry.

\section{Materials and Methods}

This prospective study was carried out in the university hospital from August 2005 to July 2007. It was approved by the hospital ethical committee. All the patients were clinically evaluated for the type of hypospadias (mid or distal), meatal stenosis, chordee, length of penis both pre- and postoperatively and associated disease.

The total number of the patients was 50 . The mean age of presentation was $5.51 \pm 2.43$ years (range $2-14$ years). Forty $(80 \%)$ patients were from a rural background and the other $10(20 \%)$

Ajay N. Gangopadhyay

Department of Pediatric Surgery

Institute of Medical Sciences, Banaras Hindu University

IN-221005 Varanasi (India)

Tel. +91 542 2309527, E-Mail gangulybhu@ rediffmail.com 
were from an urban background. The cosmetic problem was present in all patients whereas a thin urinary stream was present in 11 (22\%) patients. Chordee was present in 10 (20\%) patients.

Only patients having distal or mid penile hypospadias were included and patients of proximal penile hypospadias were excluded from the study. All patients underwent either Snodgrass or Mathieu urethroplasty. Patients having an adequate urethral plate were selected for Snodgrass urethroplasty whereas those having a poor urethral plate underwent Mathieu urethroplasty. Patients were operated upon under spinal or caudal anesthesia with sedation.

In the postoperative period, the first dressing was done on the seventh day. The presence of edema was noted. Three to seven days after the first dressing, the catheter was removed along with the dressing. Stitches were removed after 3 weeks of operation. The presence of any fistula or infection was noticed. In the follow-up, patients were examined for any spontaneous closure of fistula or development of delayed fistula, stenosis or stricture of the neourethra, meatus or diverticular formation. Appearance of the penis and urinary stream were assessed at each visit. Results of the procedure and complications, if any were noted at each visit.

Preoperative uroflowmetry was done in every patient who was able to follow our commands before operation. Postoperative uroflowmetry was done 2 weeks after stitch removal only in those patients who were not having urethral fistula. Uroflowmetry was done with a rotating disc sensor. The values studied were for the first $100 \mathrm{ml}$ of urine for the sake of comparing the values. These included maximal urine flow rate $\left(\mathrm{Q}_{\max }\right)$, average urine flow rate $\left(\mathrm{Q}_{\text {avg }}\right)$ and voiding time (VT). Postoperative dilation was done only in those patients who had decreased urinary flow as compared to preoperative values. Statistical analysis was done using SPSS software. Results were analyzed using paired t-test, independent t-test and Z-test.

\section{Results}

The mean penile length in patients both before and after release of chordee was $4.45 \pm 0.72$ and $4.80 \pm 0.75$ $\mathrm{cm}(\mathrm{p}<0.05)$.

The complications noticed were pericatheter leak and fistula in $7(14 \%)$, meatal stenosis in $9(18 \%)$ and stricture in $2(8 \%)$ patients (table 1$)$. The mean duration of follow-up was $7.57 \pm 0.12$ months (range 6-9 months).

The total number of patients in whom uroflowmetry was performed was 37. Twenty-two patients had Snodgrass urethroplasty and the other 15 had Mathieu urethroplasty. The excluded patients included those with the fistula or who were too young to follow our commands. On comparing the pre- and postoperative values, the change in all the 3 values was significant $(\mathrm{p}<0.05)$ (table 2). On comparing the 2 groups, the Snodgrass technique appeared to be relatively better than Mathieu's technique in all the 3 variables; however, on the basis of t value the difference was statistically insignificant (table 3). The requirement of dilation was more with Mathieu's tech-
Table 1. Comparative evaluation of the two surgical techniques as regard to the complications

\begin{tabular}{llll}
\hline Complications & $\mathrm{n}$ & Snodgrass & Mathieu \\
\hline Fistula & 7 & 2 & 5 \\
Meatal stenosis & 9 & 3 & 6 \\
Stricture & 2 & 1 & 1
\end{tabular}

The complications were more in the Mathieu urethroplasty group than the Snodgrass urethroplasty group.

Table 2. Uroflowmetric evaluation for $100 \mathrm{ml}$ of urine $(\mathrm{n}=37)$

\begin{tabular}{lrrrr}
\hline & Preoperative & Postoperative & $\mathrm{t}$ & $\mathrm{p}$ \\
\hline Qmax, ml/s & $6.57 \pm 2.67$ & $7.36 \pm 3.90$ & -2.653 & $<0.05$ \\
Qavg, ml/s & $4.16 \pm 1.87$ & $4.52 \pm 2.50$ & -2.336 & $<0.05$ \\
VT, $\mathrm{s}$ & $28.18 \pm 8.76$ & $26.97 \pm 9.11$ & 2.235 & $<0.05$ \\
\hline
\end{tabular}

Table 3. Postoperative uroflowmetric evaluation for $100 \mathrm{ml}$ of urine operated by Snodgrass $(n=22)$ and Mathieu's $(n=15)$ technique

\begin{tabular}{lrcr}
\hline & Snodgrass & Mathieu & $\mathrm{t}$ \\
\hline Qmax, ml/s & $7.65 \pm 3.79$ & $6.93 \pm 4.14$ & 0.550 \\
Qavg, ml/s & $4.78 \pm 2.51$ & $4.14 \pm 2.52$ & 0.759 \\
VT, s & $26.22 \pm 9.80$ & $28.06 \pm 8.19$ & 0.597 \\
\hline
\end{tabular}

On comparing the 2 groups, Snodgrass technique seems to be relatively better than Mathieu's technique in all the 3 variables; however, on basis of $t$ value the difference is statistically insignificant.

Table 4. Requirement of postoperative dilation

\begin{tabular}{llll}
\hline No. of times & $\mathrm{n}$ & Snodgrass & Mathieu \\
\hline 1 & 2 & 0 & 2 \\
2 & 4 & 2 & 2 \\
3 & 5 & 2 & 3 \\
4 & 1 & 0 & 1 \\
\hline
\end{tabular}

The requirement of dilation was more with Mathieu's technique than with Snodgrass. It was done only in patients who had decreased urine flow rates on uroflowmetry in the postoperative period. All patients responded satisfactorily to dilation. On applying $\mathrm{Z}$ test, the difference was statistically insignificant $(\mathrm{Z}=1.66$, $\mathrm{p}>0.05)$. 
nique than with Snodgrass. It was done only in patients who had decreased urine flow rates on uroflowmetry in the postoperative period. All patients responded satisfactorily to dilation. On applying the Z-test, the difference was statistically insignificant $(\mathrm{Z}=1.66, \mathrm{p}>0.05)$ (table 4).

\section{Discussion}

There has been a lot of work done in the field of hypospadias; however, the functional evaluation has been left more for clinical evaluation which can have observer bias. In the present study, this observer bias was tried to be eliminated by the use of uroflowmetry.

According to a recent review, the best time for repair of hypospadias is between 6 and 12 months of age [4]. In our study, only 3 children were 2 years old. All of them belonged to the urban background.

For dilation, only those patients with no urethral fistula were included. The requirement of dilation was more with Mathieu's technique than with the Snodgrass technique (table 4). The requirement of dilation was judged on the basis of uroflowmetry. Garibay et al. [5] operated upon various types of hypospadias with different techniques. They were able to identify meatal stenosis and stricture on the basis of uroflowmetry that responded to either dilation or surgery. Anwar et al. [6] successfully detected asymptomatic urethral strictures using uroflowmetry and treated them by urethral dilation. The same was noticed by us. No patient presented with overt urinary obstruction and subclinical obstruction was detected on uroflowmetry. Studies have found asymptomatic strictures which are diagnosed by uroflowmetry to occur more commonly in the first year after operation [7].

There are conflicting conclusions on the postoperative evaluation of hypospadias using uroflowmetry. Some have claimed to have normal flow pattern $[8,9]$, while others have found them to be obstructive [10]. We noticed an obstructive pattern, although subclinical, in 12 patients that responded to dilation. It has been reported that urinary flow obstruction after hypospadias may be a temporary phenomenon and flow may increase in a follow-up of one to a few years $[10,11]$. However, the actual clinical significance of an obstructive uroflow pattern in hypospadias patients remains unclear [12]. Despite this claim, it has also been noticed that improved flow is less than normal $[13,14]$. The spontaneous improvement in the flow rates could not be substantiated by the present study because of the short follow-up. Early uroflowmetry

Uroflowmetry in Hypospadias was performed as patients in our setup do not turn up easily once they find themselves fit. This has limited a long follow-up of the patients.

In one of very few studies where both pre- and postoperative uroflow rates were compared [15], it was observed that most of the patients with an abnormal postoperative flow also had an abnormal flow preoperatively. It was suggested that this finding might reflect a factor inherent to the condition rather than secondary to surgery. This finding, however, was not noticed in the present study.

Marte et al. [16] studied 21 patients of hypospadias operated by the Snodgrass technique. They expressed $\mathrm{Q}_{\max }$ and $\mathrm{Q}_{\text {avg }}$ as percentiles and took the 25th percentile or more as normal, 5th to 25 th percentile as equivocally obstructed and $<5$ th percentile as obstructed. This use of uroflowmetry was found to be satisfactory by them. Other workers have also found uroflowmetry to be an important tool in the follow-up of patients operated on for hypospadias that are at risk for stenosis or stricture and then requiring further treatment, either surgery or dilation $[17,18]$.

There are studies reporting better cosmetic outcome with the Snodgrass technique than with the Mathieu technique [19], however, the functional outcome of their comparison is limited only to distal penile hypospadias [12]. There has been no study comparing both mid and distal penile hypospadias. The present study found the functional outcome to be better in the Snodgrass technique than with the Mathieu technique but the results were statistically insignificant. This may be due to the small sample size. More studies are needed to confirm the statement. This is in variance to Scarpa et al. [12] who noticed better flow in patients undergoing Mathieu urethroplasty.

The present study had certain limitations. The sample size was small. The follow-up period was not a long one. The results were not compared to the normal values of uroflowmetry. Rather, the results in the form of pre- and postoperative values were compared. Besides this, uroflowmetry itself has some limitations in its use. It can only be used in toilet trained children with no obvious complication such as fistula.

The strength of this study is that this is one of the few series reporting the results of uroflowmetry performed pre- and postoperatively in patients undergoing two different kinds of hypospadias repairs.

To conclude, use of uroflowmetry to assess the functional results of hypospadias surgery can be gratifying. With avoidance of unnecessary trauma due to dilation, the cooperation of pediatric patients can be achieved.

Curr Urol 2011;5:169-172 


\section{References}

1 Snodgrass WT, Shukla AR, Canning DA: Hypospadias; in Docimo SG, Canning DA, Khoury AE (eds): The Kelalis-King-Belman textbook of clinical pediatric urology, ed 5. Informa Healthcare, 2007, pp1205-1238.

$>2$ Roodsari SS, Mulaeian M, Hiradfar M: Urethral advancement and glanuloplasty with $\mathrm{V}$ flap of the glans in the repair of anterior hypospadias. Asian J Surg 2006;29:180-184.

3 Raciborski K: Usefulness of uroflowmetry for postoperative monitoring of boys with hypospadias. Ann Acad Mad Stetin 2001;47: 207-228.

4 Marrocco G, Vallasciani S, Fiocca G, Calisti A: Hypospadias surgery: a 10-year review. Pediatr Surg Int 2004;20:200-203.

5 Garibay JT, Reid C, Gonzalez R: Functional evaluation of the results of hypospadias surgery with uroflowmetry. J Urol 1995;154: 835-836.

6 Anwar A, Kurokawa Y, Takahashi M, Yamamoto Y, Kanayama HO, Kagawa S: Functional evaluation of one-stage urethroplasty with parameatal foreskin flap repair of hypospadias using uroflowmetry. Int J Urol 2003; 10:297-301.

7 Tuygun C, Bakirtas H, Gucuk A, Cakici H, Imamoglu A: Uroflow findings in older boys with tubularized incised-plate urethroplasty. Urol Int 2009;82:71-76.
-8 Hammouda HM, El-Ghoneimi A, Bagli DJ, McLorie GA, Khoury AE: Tubularized incised plate repair: functional outcome after intermediate followup. J Urol 2003;169:331333.

-9 Braga LH, Pippi Salle JL, Lorenzo AJ, Skeldon S, Dave S, Farhat WA, Khoury AE, Bagli DJ: Comparative analysis of tubularized incised plate versus onlay island flap urethroplasty for penoscrotal hypospadias. J Urol 2007;178:1451-1456.

10 Holmdahl G, Karstrom L, Abrahamsson K, Doroszkiewicz M, Sillen U: Hypospadias repair with tubularized incised plate. Is uroflowmetry necessary postoperatively? J Pediatr Urol 2006;2:304-307.

-11 Andersson M, Doroszkiewicz M, Arfwidsson C, Abrahamsson K, Holmdahl G: Hypospadias repair with tubularized incised plate: Does the obstructive flow pattern resolve spontaneously? J Pediatr Urol 2011;7:441-445.

12 Scarpa MG, Castagnetti M, Berrettini A, Rigamonti W, Musi L: Urinary function after Snodgrass repair of distal hypospadias: comparison with the Mathieu repair. Pediatr Surg Int 2010;26:519-522.

13 Wolffenbuttel K, Oudshoorn F, Hoefnagels J, van der Toorn F, Scheepe J, van den Hoek J, Kok D: Improved but still low flow rates 5 years after TIP-hypospadias repair (abstract). J Pediatr Urol 2009;5(supl 1):S58.
14 Eassa W, Almodhen F, Brzezinski A, Capolichio JP, Jednak R, el Sherbiny M: How do toilet-trained kids void following tubularized incised plate repair of hypospadias? (abstract) J Pediatr Urol 2009;5(supl 1):S59.

15 Wolffenbuttel KP, Wondergem N, Hoefnagels JJ, Dieleman GC, Pel JJ, Passchier BT, de Jong BW, van Dijk W, Kok DJ: Abnormal urine flow in boys with distal hypospadias before and after correction. J Urol 2006;176: 1733-1736.

16 Marte A, Di Iorio G, De Pasquale M, Cotrufo AM, Di Meglio D: Functional evaluation of tubularized-incised plate repair of midshaftproximal hypospadias using uroflowmetry. BJU Int 2001;87:540-543.

17 Garignon C, Chamond C, Lefebure B, Halim Y, Mitrofanoff P, Liard A: Uroflowmetric functional evaluation of modified Duplay procedure in hypospadias surgery. Prog Urol 2004;14:1199-1202.

18 Saggiomo G, Meglio D, Di Iorio G, Zamparelli M, Linetti V, Ardimento G, Cotrufo AM, Marte A: Value of uroflowmetry in a long-term follow-up study in hypospadias surgery. Minerva Pediatr 1998;50:461-465.

19 Guo Y, Ma G, Ge Z: Comparison of the Mathieu and the Snodgrass urethroplasty in distal hypospadias repair. Zhonghua Nan Ke Xue 2004;10:916-918. 